\title{
Molecular and clinical analyses of 16q24.1 duplications involving FOXF1 identify an evolutionarily unstable large minisatellite
}

\author{
Avinash V Dharmadhikari ${ }^{1,2}$, Tomasz Gambin ${ }^{2}$, Przemyslaw Szafranski ${ }^{2}$, Wenjian Cao ${ }^{2}$, Frank J Probst ${ }^{2}$, \\ Weihong Jin², Ping Fang ${ }^{2}$, Krzysztof Gogolewski ${ }^{3}$, Anna Gambin³,4, Jaya K George-Abraham5, Sailaja Golla ${ }^{6}$, \\ Francoise Boidein ${ }^{7}$, Benedicte Duban-Bedu $^{8}$, Bruno Delobel $^{8}$, Joris Andrieux ${ }^{9}$, Kerstin Becker $^{10}$, \\ Elke Holinski-Feder ${ }^{10}$, Sau Wai Cheung ${ }^{2}$ and Pawel Stankiewicz ${ }^{1,2^{*}}$
}

\begin{abstract}
Background: Point mutations or genomic deletions of FOXF1 result in a lethal developmental lung disease Alveolar Capillary Dysplasia with Misalignment of Pulmonary Veins. However, the clinical consequences of the constitutively increased dosage of FOXF1 are unknown.

Methods: Copy-number variations and their parental origin were identified using a combination of array CGH, long-range PCR, DNA sequencing, and microsatellite analyses. Minisatellite sequences across different species were compared using a gready clustering algorithm and genome-wide analysis of the distribution of minisatellite sequences was performed using R statistical software.

Results: We report four unrelated families with 16q24.1 duplications encompassing entire FOXF1. In a 4-year-old boy with speech delay and a caf-au-lait macule, we identified an $\sim 15 \mathrm{~kb} 16 \mathrm{q} 24.1$ duplication inherited from the reportedly healthy father, in addition to a de novo $1.09 \mathrm{Mb}$ mosaic 17q11.2 NF1 deletion. In a 13-year-old patient with autism and mood disorder, we found an $\sim 0.3 \mathrm{Mb}$ duplication harboring FOXF1 and an $\sim 0.5 \mathrm{Mb} 16 \mathrm{q} 23.3$ duplication, both inherited from the father with bipolar disorder. In a 47-year old patient with pyloric stenosis, mesenterium commune, and aplasia of the appendix, we identified an $\sim 0.4 \mathrm{Mb}$ duplication in 16q24.1 encompassing 16 genes including FOXF1. The patient transmitted the duplication to her daughter, who presented with similar symptoms. In a fourth patient with speech and motor delay, and borderline intellectual disability, we identified an 1.7 Mb FOXF1 duplication adjacent to a large minisatellite. This duplication has a complex structure and arose de novo on the maternal chromosome, likely as a result of a DNA replication error initiated by the adjacent large tandem repeat. Using bioinformatic and array CGH analyses of the minisatellite, we found a large variation of its size in several different species and individuals, demonstrating both its evolutionarily instability and population polymorphism.
\end{abstract}

Conclusions: Our data indicate that constitutional duplication of FOXF1 in humans is not associated with any pediatric lung abnormalities. We propose that patients with gut malrotation, pyloric or duodenal stenosis, and gall bladder agenesis should be tested for FOXF1 alterations. We suggest that instability of minisatellites greater than $1 \mathrm{~kb}$ can lead to structural variation due to DNA replication errors.

Keywords: cis-regulation, Satellite repeats, Microhomology-mediated break-induced replication, Microduplication

\footnotetext{
* Correspondence: pawels@bcm.edu

Equal contributors

'Interdepartmental Program in Translational Biology \& Molecular Medicine,

Baylor College of Medicine, Houston, TX, USA

2Department of Molecular and Human Genetics, Baylor College of Medicine,

One Baylor Plaza, Houston, TX 77030, USA

Full list of author information is available at the end of the article
}

\section{() Biomed Central}

2014 Dharmadhikari et al.; licensee BioMed Central. This is an Open Access article distributed under the terms of the Creative Commons Attribution License (http://creativecommons.org/licenses/by/4.0), which permits unrestricted use, distribution, and reproduction in any medium, provided the original work is properly credited. The Creative Commons Public Domain Dedication waiver (http://creativecommons.org/publicdomain/zero/1.0/) applies to the data made available in this article, unless otherwise stated. 


\section{Background}

Heterozygous point mutations and genomic deletions involving the dosage-sensitive FOXF1 gene on chromosome 16q24.1 have been reported as causative in patients with a rare, neonatally-lethal developmental lung disorder Alveolar Capillary Dysplasia with Misalignment of Pulmonary Veins (ACDMPV; OMIM 265380) [1-5]. The majority of patients with ACDMPV also have extra-pulmonary anomalies of the gastrointestinal, cardiovascular, or genitourinary systems. In a number of ACDMPV patients negative for mutation and deletion in FOXF1, we identified overlapping genomic deletions mapping upstream of FOXF1. These deletions enabled us to define an $\sim 60 \mathrm{~kb}$ noncoding, evolutionarilyconserved, and differentially-methylated cis-regulatory enhancer region that maps $\sim 272 \mathrm{~kb}$ upstream of FOXF1 and harbors lung-specific long non-coding RNA (lncRNA) genes [6,7]. Recently, we demonstrated that the FOXF1 locus in humans is incompletely paternally-imprinted in the lungs, and that the imprinting likely involves these lncRNAs [6,8]. Moreover, the antisense lncRNA gene, FENDRR, located $5 \mathrm{~kb}$ upstream of FOXF1, was found to associate with the polycomb repressive complex (PRC)2 and negatively regulate FOXF1 expression [9].

$F_{0 x} \mathrm{f1}^{-1-}$ mice die by embryonic day (e) 8.5 due to vascular abnormalities that stem from defects in mesodermal differentiation and cell adhesion [10]. Approximately 50-90\% of the heterozygous Fox $\mathrm{f}^{+/-}$mice, depending on their genetic background, die neonatally due to respiratory failure $[11,12]$. Endothelium specific homozygous knockout of Foxf1 using Tie2-cre and Pdgfb-CreER leads to embryonic lethality around e13.5-e16.5 due to vascular abnormalities in the lung, placenta and yolk sac [13]. Endothelial specific deletion of Foxf1 causes decreased expression of endothelial genes critical for vascular development, including VEGF receptors Flt1 and Flk1, Pdgfb, Pecam1, CD34, integrin $\beta 3$, ephrin B2, Tie2 and Fendrr. Interestingly, homozygous loss of Fendrr in mice was shown to be either embryonic lethal due to heart and body wall defects [14], or perinatal lethal due to multiple defects in lung, heart, or gastrointestinal tract [15].

Previous studies have shown FOXF1 to be epigenetically inactivated in breast cancer, suggesting its potential role as a tumor suppressor gene [16]. Common variants mapping on chromosome 16q24.1 close to FOXF1 have also been associated with susceptibility to Barretts esophagus in genome-wide association studies $[17,18]$. Up-regulation of FOXF1 has been reported in breast cancer [19], rhabdomyosarcoma [20], and in colorectal adenocarcinomas [21]. However, the clinical consequences of constitutively increased dosage of FOXF1 remain unknown.

Variable Number Tandem Repeats (VNTRs) with repeat units less than nine nucleotides (nt) are referred to as microsatellites, those with repeat units between 10 and $100 \mathrm{nt}$ are defined as minisatellites and those with repeat units greater than $100 \mathrm{nt}$ are termed macrosatellites or megasatellites. VNTRs are extremely unstable, with mutation rates 10-100,000 times higher than nonrepeat sequences. They tend to be highly polymorphic, expanding or contracting due to DNA strand replication or recombination slippage $[22,23]$.

Using chromosomal microarray analysis, we identified and molecularly characterized overlapping 16q24.1 duplications harboring entire FOXF1 in four unrelated families. In addition, we describe an evolutionarily unstable large minisatellite on chromosome 16q24.1, likely responsible for the formation of one of these duplications.

\section{Methods}

\section{Subject recruitment}

Patients 1 and 2 were referred for clinical chromosomal microarray testing in the Medical Genetics Laboratories (MGL) at Baylor College of Medicine (BCM). Patient 3 was referred for genetic counseling to the Medical Genetics Center, Munich, Germany. Patient 4 was reported in Decipher (265898) and was referred for clinical chromosomal microarray testing at the Saint Vincent de Paul Catholic Hospitals Association of Lille, Free Faculty of Medicine, Lille, France. The twelve 16q24.1 non-duplicated control samples were obtained from clinical diagnostic testing at MGL or ACDMPV research study at BCM.

\section{Patients}

Patient 1 is a $42 / 12$ year old boy, the third child of a non-consanguineous 20-year-old mother and 22-year old father. Maternal complications prior to delivery included placenta previa. He was born at term via spontaneous vaginal delivery with birth weight of $3.2 \mathrm{~kg}$. He sat unassisted at 5 months and began walking at 9 months. At the age of 28 months, the probands height was $93 \mathrm{~cm}\left(72^{\text {nd }}\right.$ percentile), weight was $14.5 \mathrm{~kg}$ ( $78^{\text {th }}$ percentile), and head circumference was $29.5 \mathrm{~cm}\left(44^{\text {th }}\right.$ percentile). He has mildly dysmorphic facial features, with a broad forehead, sparse eyebrows, mildly low-set ears, and nasal features with small alae, broad tip and broad bridge. He has brachydactyly of fingers and toes. There is one caf-au-lait macule on his left flank. He has speech delay, is very limited in the number of words used, and was found to be anxious, hyperactive, uncooperative, aggressive, and impulsive. He tends to sweat a lot, especially at night, and has bedwetting. Every two to three weeks he complains of abdominal pain and feels nauseous, but does not vomit. Pulmonary findings are normal on physical examination, with the lungs clear to auscultation bilaterally without wheezes, rhonchi, or rales. He has had numerous viral upper respiratory infections and was hospitalized around 18 months of age 
for pneumonia. Both the father and mother are reportedly in good health and have had no learning, speech, or lung problems. Paternal grandparental samples were not available.

Patient 2 is a 13-year-old boy, who based on Diagnostic and Statistical Manual Fifth edition (DSM-V) was diagnosed with autism, unspecified mood and anxiety disorder, pervasive developmental disorder not otherwise specified and emotional disorder. At the age of 12 years, his height was $141.5 \mathrm{~cm}$ (12th percentile), weight was $32.95 \mathrm{~kg}\left(10^{\text {th }}\right.$ percentile), and head circumference was $52.5 \mathrm{~cm}\left(24^{\text {th }}\right.$ percentile). He is extremely aggressive and has poor social skills. He makes poor eye contact and has fine motor skill delays. There was no evidence of any lung abnormalities except for a remote history of asthma. His father was diagnosed with bipolar disorder.

Patient 3 is a 47-year-old female patient, who at the age of 2 years presented with recurrent vomiting and was subsequently diagnosed with pyloric stenosis, mesenterium commune, and aplasia of the appendix. Her height was $168 \mathrm{~cm}$ ( $49^{\text {th }}$ percentile), weight was $58 \mathrm{~kg}\left(47^{\text {th }}\right.$ percentile), and head circumference was $56 \mathrm{~cm}\left(71^{\text {st }}\right.$ percentile). Psychomotor development was normal. At the age of 34 years, she had a postpartum iliofemoral deep vein thrombosis on the left side with pulmonary embolism. Factor V Leiden mutation, Prothrombin G20210A mutation, antithrombin deficiency, protein $\mathrm{C}$ deficiency and protein $\mathrm{S}$ deficiency were excluded. At the age of 42 years, the patient was diagnosed with multiple sclerosis. Her 13year-old daughter presented with pyloric stenosis with bowel malrotation, aplasia of the caecum and appendix, mesenterium commune, gastroesophageal reflux disease, as well as persistent foramen ovale, unilateral inguinal hernia, and immature hip development. Her height was 162 $\mathrm{cm}$ (53 ${ }^{\text {rd }}$ percentile), weight was $49 \mathrm{~kg}$ (42 ${ }^{\text {nd }}$ percentile), and head circumference was $55 \mathrm{~cm}$ ( $73^{\text {rd }}$ percentile). Dumping syndrome, relative short bowel syndrome, failure to thrive, and dystrophy were noted. Psychomotor development was normal. There was no evidence for any lung abnormalities in the two patients. Patient $3 \mathrm{~s}$ father presented with hematemesis and anemia in infancy. Laparotomy at the age of 6 years revealed pyloric stenosis, bowel malrotation, mesenterium commune, and aplasia of the caecum and appendix. In childhood, a caput medusa was noted, and at the age of 18 years, venous ulcers of the legs were observed. Before the age of 50, the father had several iliofemoral deep venous thromboses and inferior vena cava atresia was suspected. At the age of 34 years, a Billroths operation II was performed because of a hemorrhagic duodenal ulcer. He was diagnosed with iron-deficiency anemia, protein $\mathrm{S}$ deficiency, activated protein $\mathrm{C}$ resistance, and renal insufficiency. The fathers DNA was not available for testing.
Patient 4 is a 10 1/12-year-old boy born to healthy and non-consanguineous 23 and 25 year-old parents. His height, weight, and head circumference were $135.5 \mathrm{~cm}$ (between the $25^{\text {th }}$ and $50^{\text {th }}$ percentile), $29.3 \mathrm{~kg}$ (between the $25^{\text {th }}$ and $50^{\text {th }}$ percentile), and $52 \mathrm{~cm}$ (between the $10^{\text {th }}$ and $25^{\text {th }}$ percentile), respectively. During the pregnancy, he was diagnosed with a club foot, which was surgically corrected. He presented with speech delay, motor delay, and borderline intellectual disability (ID). No respiratory or cardiac defects were observed. Pedigrees of families 2 and 3 are shown in Additional file 1: Figure S1.

\section{DNA isolation}

Genomic DNA was extracted from peripheral blood via the Puregene DNA isolation kit (Gentra System, Minneapolis, MN, USA) (patients 1 and 2), FlexiGene DNA Kit (Qiagen, Valencia, CA) (patient 3) and QIAamp DNA mini kit (Qiagen, Valencia, CA) (patient 4).

\section{Array CGH analysis}

Chromosomal microarray analysis (CMA) in patients 1 and 2 were performed using array CGH $(\mathrm{aCGH})$ with custom-designed exon targeted aCGH oligonucleotide microarrays V8.1.1 OLIGO, 180K and V9.1.1 OLIGO, 400K, respectively, designed by the MGL at BCM (http://www. bcm.edu/geneticlabs/) and manufactured by Agilent Technology (Santa Clara, CA, USA) as described [24]. In patient 3, aCGH analysis was performed using an Oligonucleotide array (Cytochip v1.0 180K, BlueGnome, Cambridge, GRCh37, Ensembl Release 70) and in patient $3 \mathrm{~s}$ daughter, aCGH analysis was done using Illumina SNP-Array (Infinium CytoSNP-850K; GRCh37). aCGH in patient 4 was performed using a $860 \mathrm{~K}$ microarray (Agilent Technology). Fine duplication mapping was performed in patient 1 using aCGH with a customdesigned 16q24.1-specific $720 \mathrm{~K}$ microarray covering $2-\mathrm{Mb}$ regions flanking FOXF1 [Roche-NimbleGen (Madison, WI, USA)] as described [25], and in patients 2 and 4 using a custom-designed 16q24.1 regionspecific 4 180K microarray (Agilent Technology), as described [6].

\section{FISH analysis}

Confirmatory fluorescence in situ hybridization (FISH) analyses were performed using the standard procedures.

\section{Long-range PCR and DNA sequence analysis}

The junction fragments of the duplications were amplified using long-range PCR with Takara LA Taq Polymerase (TaKaRa Bio USA, Madison, WI, USA) according to the manufacturers instructions. Primers were designed using Primer3 software (http://frodo.wi.mit.edu/primer3/), at the apparent head-to-tail duplication boundaries inferred from the 16q24.1 custom-designed array CGH 
analysis. PCR products were visualized on a $1 \%$ agarose gel, purified with ExoSAP-IT (USB, Cleveland, OH, USA) to remove unconsumed dNTPs and primers, and directly sequenced via Sanger method (Lone Star Labs, Houston, TX, USA).

\section{Microsatellite analysis}

Microsatellite markers D16S539, D16S488, D16S486, D16S520, and D16S3074 for parental studies were PCR amplified and analyzed by capillary electrophoresis (SeqWright, Houston, TX), followed by analysis using the GeneMapper software (Applied Biosystems, Foster City, CA).

\section{Bioinformatic and in silico DNA sequence analyses}

Genomic sequences determined based on oligonucleotide coordinates from aCGH experiments were downloaded from the UCSC genome browser (NCBI build 37/hg19, http://genome.ucsc.edu) and assembled using Sequencher 4.8 software (Gene Codes Corporation, Ann Arbor, MI, USA). Interspersed repeat sequences were identified using RepeatMasker (http://www.repeatmasker.org).

To determine the occurrence of polymorphism in the minisatellite region in the general population, the Database of Genomic Variants: Structural Variation track in the UCSC genome browser was used. Orthologous VNTR sequences to the minisatellite sequence in other genomes were obtained using the convert and blat functions in the UCSC genome browser.

To compare and visualize syntenic sequences among different organisms, main repeated motifs were extracted and subjected to pairwise alignment. Repeats composing each sequence were aligned to form one set consisting of all existing motifs among the considered species. The resulting set was clustered into several groups using the gready clusterization algorithm: the most numerous motifs were assumed to be centers, while number of differences was assumed to be metric. One cluster contains motifs that differ from the center-motif with at most four point mutations and four point deletions.

Locations and sizes of VNTRs in the human genome, identified by Tandem Repeats Finder (TRF: http://tandem. bu.edu/trf/trf.submit.options.html) were downloaded from the Simple Tandem Repeats track in the UCSC genome browser [26]. Distances of VNTRs from the nearest centromere and telomere were calculated using the $\mathrm{R}$ statistical program (http://cran.r-project.org).

\section{Results}

Array CGH, FISH, Long-range PCR and DNA sequence analyses

The 16q24.1 duplications involving FOXF1 in patients 1-4 are shown in Figure 1.

\section{Family 1}

In patient 1, CMA with V8.1.1 OLIGO revealed a 4$109 \mathrm{~kb}$ duplication on chromosome 16q24.1 involving FOXF1 and an $\sim 1.09 \mathrm{Mb}$ mosaic deletion of the NF1 region on chromosome 17q11.2. The 16q24.1 duplication was also found by CMA in the patients father. NF1 deletions are classified into type I caused by nonallelic homologous recombination (NAHR) during meiosis and type II arising from NAHR during mitosis and associated with a high frequency of somatic mosaicism $[27,28]$. Unfortunately, the resolution of our clinical array did not allow for distinguishing between these two kinds of deletions. Custom-designed high-resolution region-specific aCGH analyses demonstrated that the $16 \mathrm{q} 24.1$ duplication is $\sim 15 \mathrm{~kb}$ in size (Figure 2a). FISH analysis in patient 1 with the BAC clone RP11-142O6 showed that the NF1 deletion in $17 \mathrm{q} 11.2$ is mosaic and present in $37 \%$ of blood cells examined. Using long-range PCR (LR-PCR) with primers F1 and R1 (Additional file 1: Table S1), the proximal breakpoint of the 16q24.1 duplication was mapped at chr16:86,539,970-86,539,977 (hg19) and the distal breakpoint was mapped at chr16:86,555, 608-86,555,615, defining a 15,645 bp tandem head-to-tail duplication. The duplication harbors the entire FOXF1 gene, its promoter, and exon 1 of the lncRNA FENDRR. DNA sequence analysis of the junction fragment revealed 8 bp GTGGTCAG microhomology (Figure 2b). The distal breakpoint is located within a SINE/MIR repetitive element and the proximal breakpoint within a unique sequence. Schematic representation of the strategy used to amplify the duplication breakpoint junction fragment is shown in Figure 2c.

\section{Family 2}

In patient 2, CMA identified a copy-number gain of chromosome band 16q23.3 spanning 505-592 kb followed by another copy-number gain of the nearby $16 q 24.1$ region spanning 265-327 kb and harboring FOXF1. Both duplications were inherited from the father. Customdesigned high-resolution aCGH analyses refined the duplication coordinates to chr16:82,215,062-82,728,565 (0.51 Mb; 16q23.3), involving an upstream portion of CDH13 and chr16:86,286,094-86,714,315 (0.43 Mb; 16q24.1), harboring entire FOX gene cluster with FOXF1, FOXC2, and FOXL1. Additionally, custom-designed highresolution aCGH analyses identified a third $\sim 52 \mathrm{~kb}$ duplication at 16q24.2 (chr16:87,510,166-87,562,249) (Figure 3a).

\section{Family 3}

In patient 3, CMA identified a $417 \mathrm{~kb}$ copy-number gain of chromosome band 16q24.1 (chr16:86,211,060-86,628,524), encompassing 16 genes, including FOXF1 (Additional file 1: Figure S2). G-banded chromosomal analysis was normal. Array $\mathrm{CGH}$ analysis in patient $3 \mathrm{~s}$ daughter 


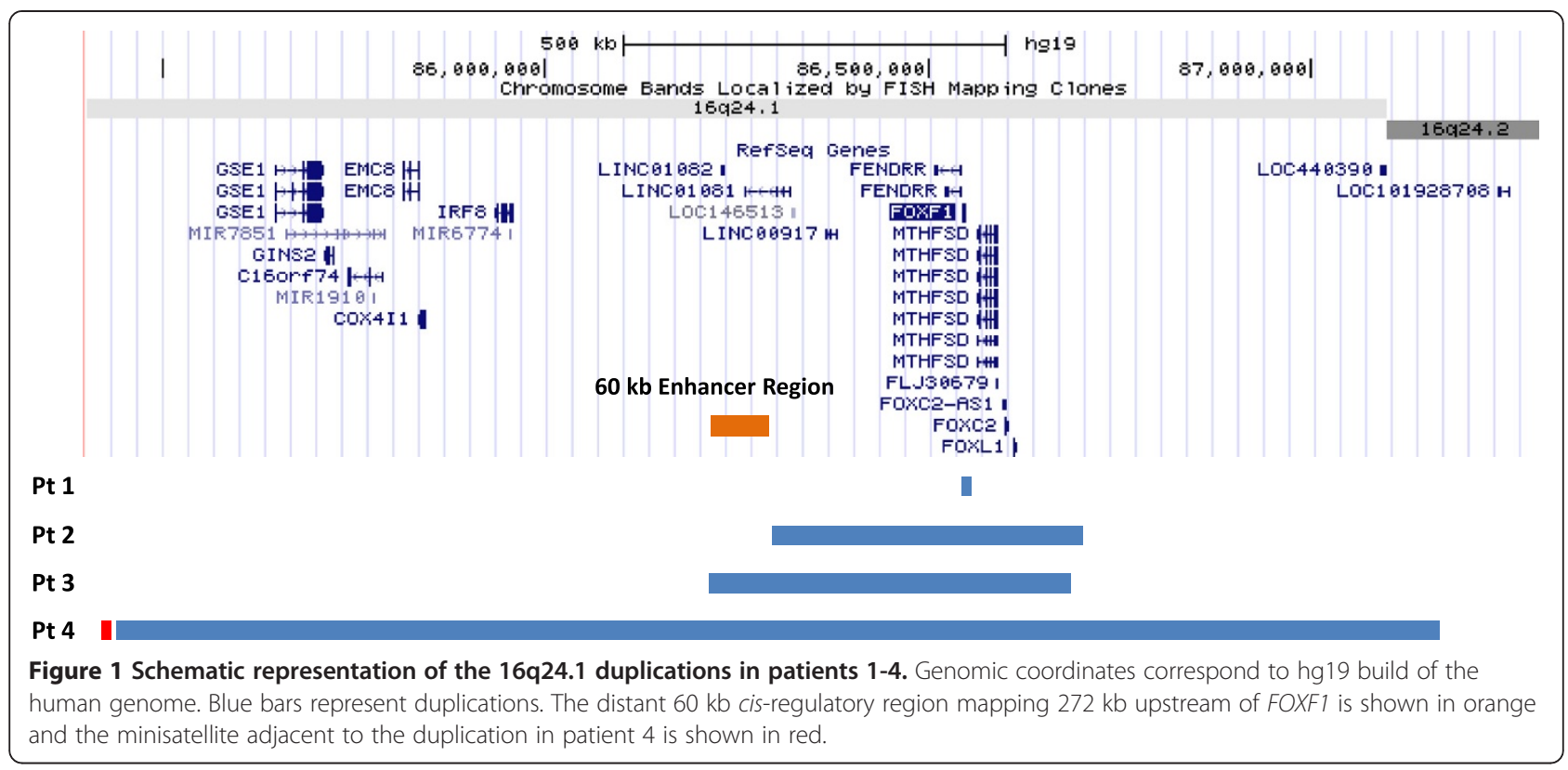

revealed the same 16q24.1 duplication (chr16: 86,198, 252-86,640,349); differences in coordinates are due to a different array platform (Figure 3b). Using LR-PCR with primers F3 and R3 (Additional file 1: Table S1), the proximal breakpoint of the $16 \mathrm{q} 24.1$ duplication was mapped at chr16:86,194,788-86,194,790 and the distal breakpoint at chr16:86,642,276-86,642,278, defining a
447,488 bp tandem head-to-tail duplication (Figure 3c). DNA sequence analysis of the junction fragment revealed $3 \mathrm{bp}$ AGA microhomology (Figure 3d).

\section{Family 4}

In patient $4,860 \mathrm{~K}$ microarray revealed a $1.65-1.80 \mathrm{Mb}$ 16q24.1 duplication. Our customized array enabled

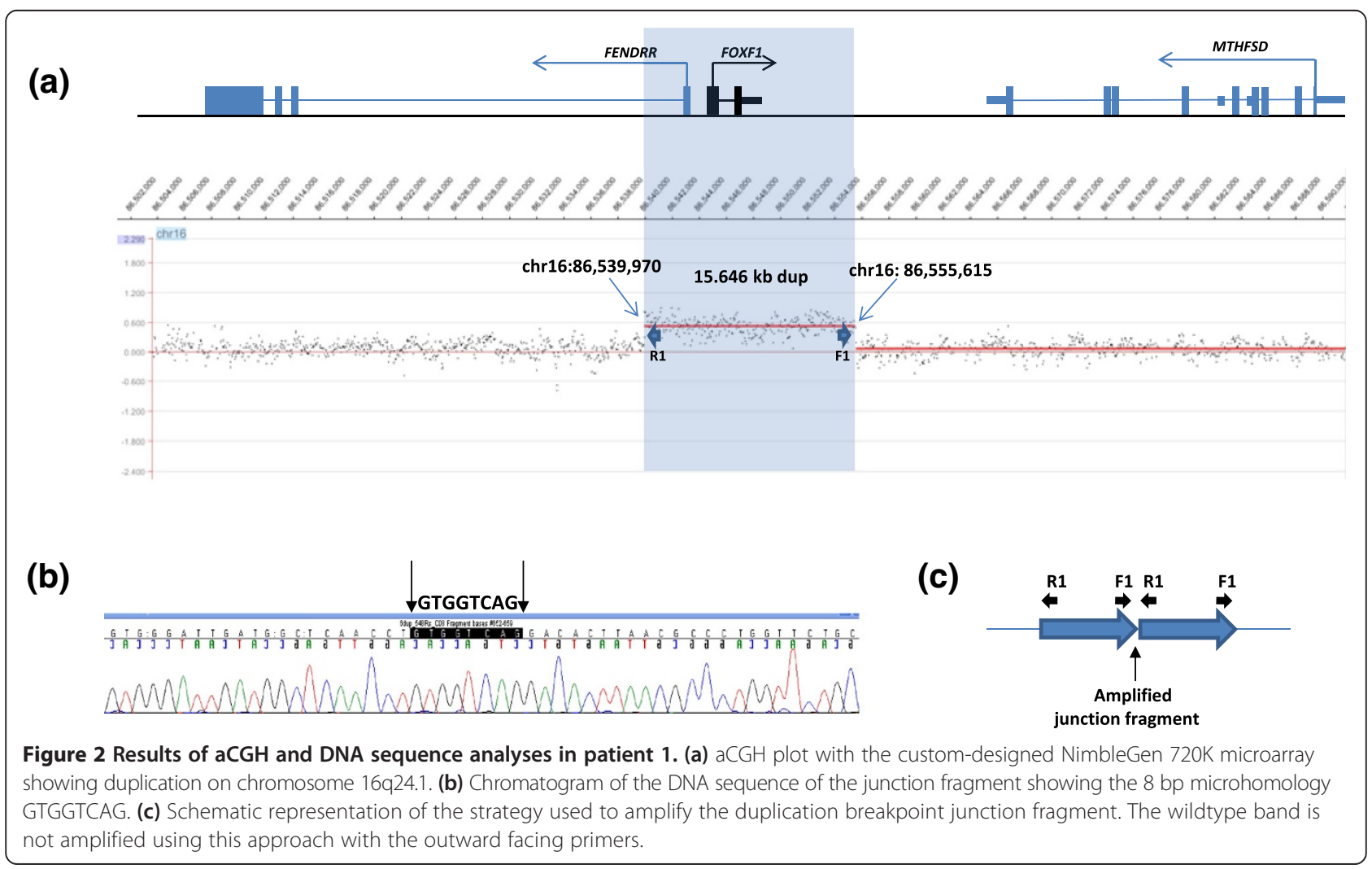




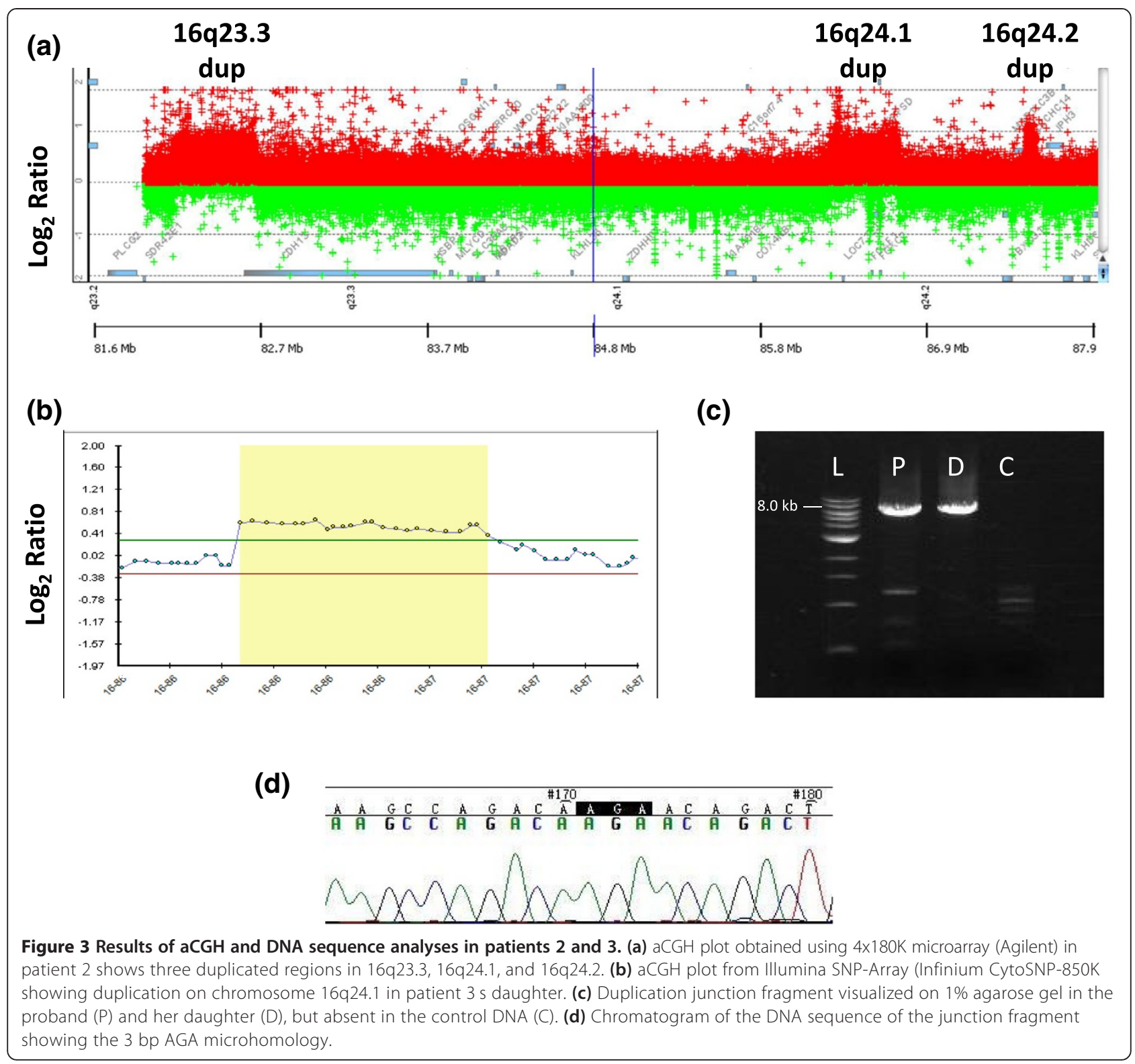

narrowing the duplication breakpoints to chr16:85, $447,996-87,167,963$, adjacent and distal to a large minisatellite (chr16:85,437,712-85,446,335; 8.6 kb) (Figure 4a, b). FISH analysis with the BAC clone RP11-514D23 confirmed the 16q24.1 duplication and excluded an insertional translocation (Figure 4c).

The duplication breakpoints were mapped using LR-PCR with primers F4 and R4 (Figure 4d, Additional file 1: Table S1). Sequence analysis of the breakpoint junction fragment revealed additional complexity, including truncated segments of the minisatellite sequence (chr16:85,437,697-85,446,384), an 8 bp insertion, and two other junctions with microhomologies (Additional file 1: Figure S3). Due to the highly repetitive nature of the minisatellite, it was not possible to sequence the breakpoints located within it.

\section{Analysis of non-human primates}

LR-PCR applied across the tandem repeats in Chimp (Pan troglodytes) and Rhesus (Macaca mulatta) genomes revealed the evolutionarily polymorphic nature of the repeat (Additional file 1: Figure S4).

\section{Microsatellite analysis}

Microsatellite analysis in patient 4 was informative for markers D16S486, D16S520, and D16S3074 and showed that the duplication arose on the maternal chromosome (Table 1, Additional file 1: Figure S5). 


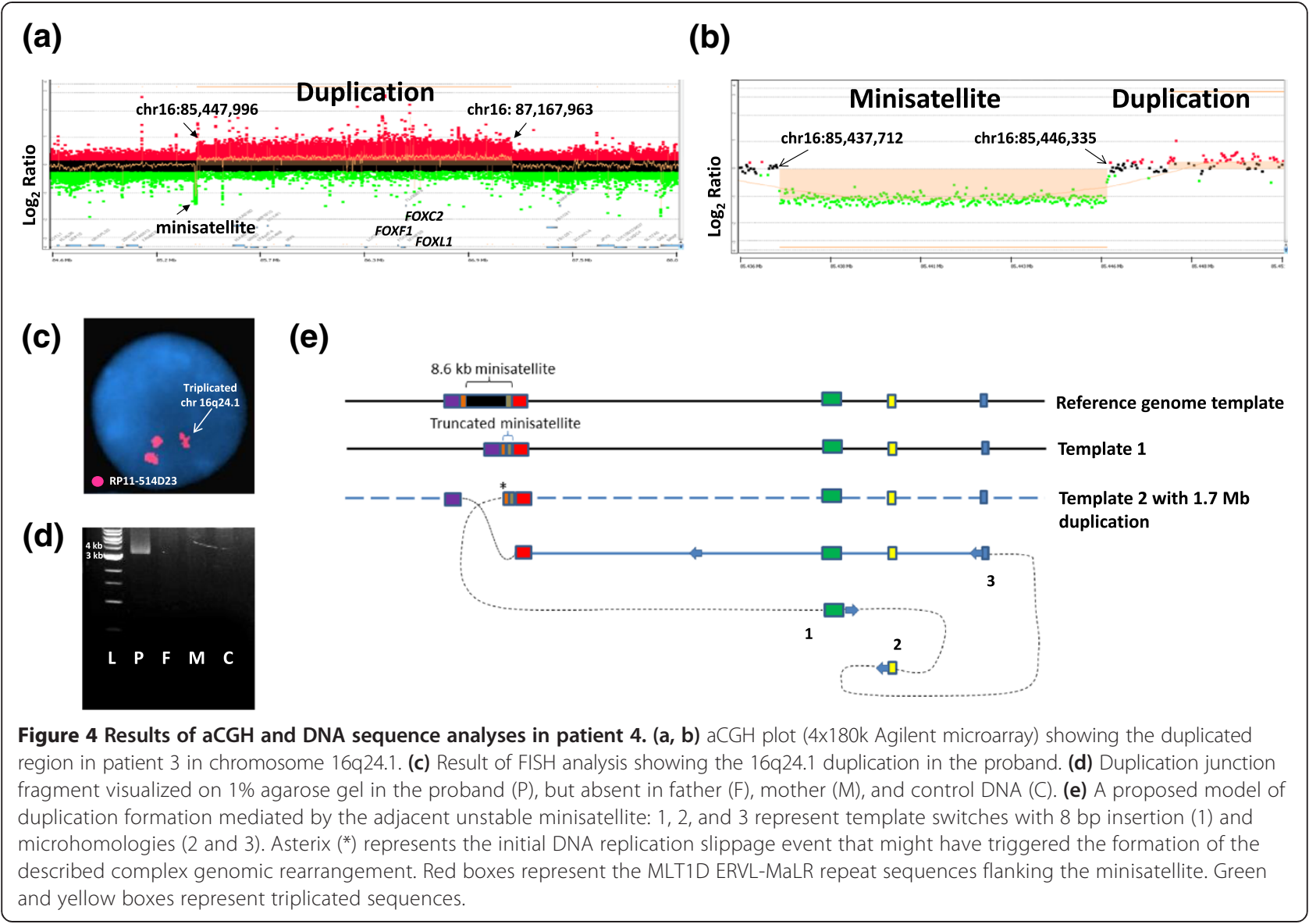

Minisatellite-Bioinformatic and aCGH analyses

In the reference human genome, the large minisatellite is $8,688 \mathrm{~kb}$ in size, consisting of imperfect repeats of $33 \mathrm{bp}$ sequence CAGGGCCCCCCGGATAATCCTCACTGTT ACACT and is flanked by MLT1D ERVL-MaLR repeat sequences. Comparison of the aCGH results for this region in patient 4 with control samples run on highresolution 16q24.1 arrays revealed the polymorphic nature of this tandem repeat (Figure 5, Additional file 1: Figure S6). In addition, several variants of this region are reported in the Database of Genomic Variants (DGV) (Additional file 1: Figure S7). Use of convert and blat functions in the UCSC genome browser showed the presence of orthologous VNTRs in several genomes across species (Table 2, Figure 6). Of note, in a few species, more than one homologous non-syntenic loci were identified, further suggesting their evolutionary instability.

Genome-wide bioinformatics analyses showed that in contrast to VNTRs shorter than $1 \mathrm{~kb}$, minisatellites longer than $1 \mathrm{~kb}$ cluster at pericentromeric and subtelomeric regions (Additional file 1: Figure S8). The distribution of VNTRs greater than $1 \mathrm{~kb}, 3 \mathrm{~kb}$, and $5 \mathrm{~kb}$ in size across all chromosomes is shown in Additional file 1: Figure S9.

\section{Discussion}

In humans, FOXF1 expression is restricted to the fetal and adult lungs, prostate, and placenta. Unfortunately, we do not have RNA samples from these organs to

Table 1 Fragment analysis for microsatellite markers on 16q24.1 in patient 4 and his unaffected parents

\begin{tabular}{lllll}
\hline Microsatellite marker & Genomic coordinates (hg19) & Patient 4 s genotype & Father s genotype & Mother s genotype \\
\hline D16S539 & chr16:86,386,034-86,386,428 & $146 / 146$ & $146 / 158$ & $146 / 162$ \\
D165488 & chr16:86,386,286-86,386,641 & $236 / 236$ & $236 / 248$ & $236 / 252$ \\
D165486 & chr16:86,490,068-86,490,708 & $380 / \mathbf{3 8 4}$ & $377 / 380$ & $380 / 384$ \\
D16S520 & chr16:86,516,112-86,516,335 & $195 / \mathbf{1 8 3}$ & $181 / 195$ & $183 / 183$ \\
D16S3074 & chr16:87,084,745-87,085,073 & $188 / \mathbf{2 1 7}$ & $188 / 211$ & $188 / 217$ \\
\hline
\end{tabular}

Informative alleles inherited from the mother are shown in bold. 

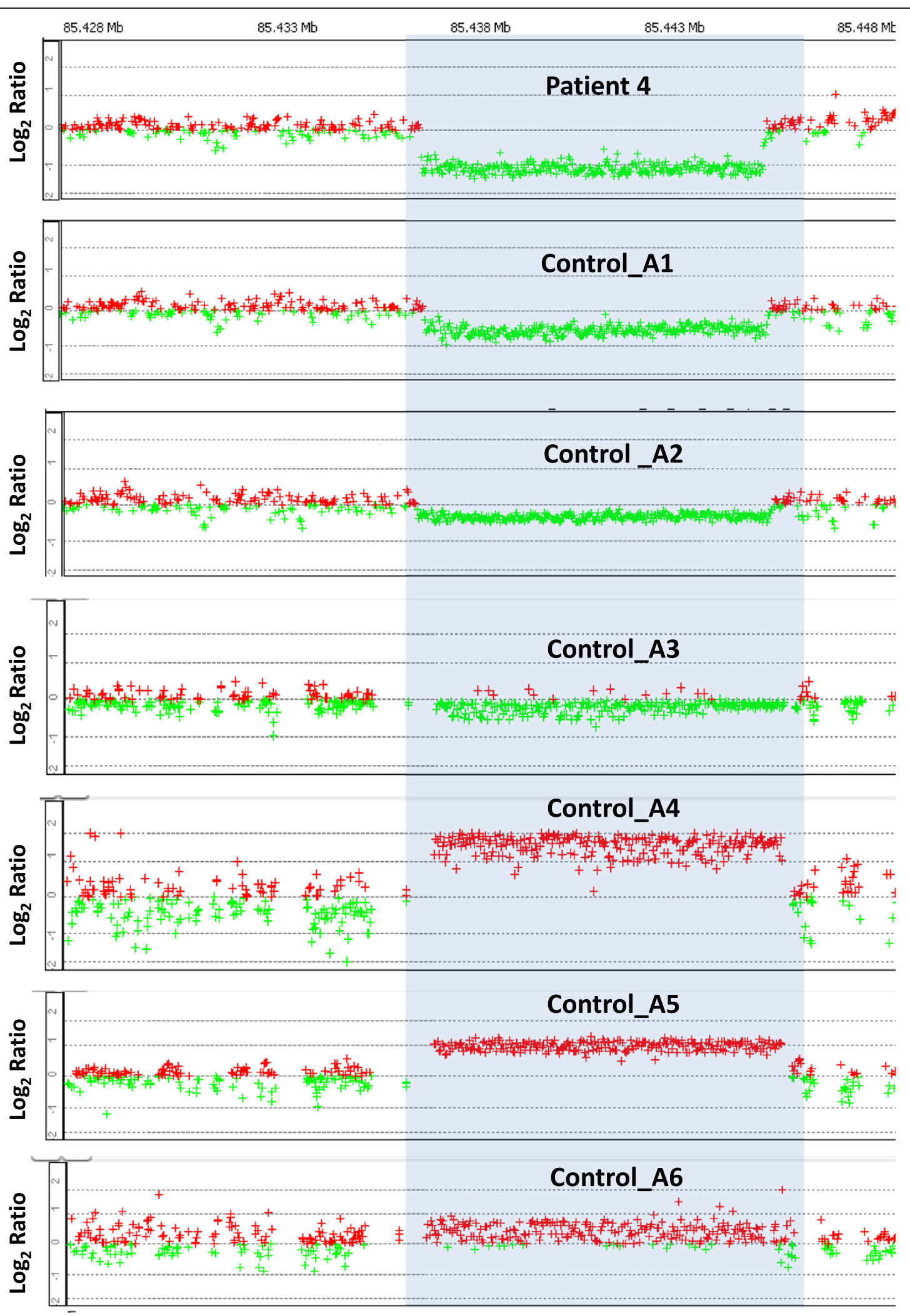

Figure 5 High-resolution custom-designed region-specific Agilent CGH microarray analyses of the studied minisatellite in 16q24.1. aCGH plot for patient 4 and 6 non-duplicated control samples run on 4x180k 16q24.1-specific Agilent microarray. Due to the repetitive nature of the minisatellite, contraction or expansion of the minisatellite shows decrease or increase in log ratios for all oligo probes in this region. 
Table $\mathbf{2}$ Location of orthologous sequences to the $\mathbf{8 . 6} \mathbf{~ k b}$ minisatellite across species

\begin{tabular}{|c|c|c|c|}
\hline Species & Orthologous genomic coordinates & Other genomic locations & Genome build \\
\hline Human & chr16:85,437,697-85,446,384 (8688bp) & N/A & hg19 \\
\hline \multirow[t]{2}{*}{ Chimp } & chr16(+):85,057,404-85,058,000 (597bp) & chr6(-):171,902,631-171,903,434 (804bp) & CSAC 2.1.4/panTro4 \\
\hline & & chr16(-):87,565,917-87,566,290 (374bp) & \\
\hline Gorilla & chr16(+):75,975,460-75,975,529 (70bp) & $\operatorname{chr} 7(+): 156,341,820-156,342,473$ (654bp) & gorGor3.1/gorGor3 \\
\hline Orangutan & chr16(+):73,141,772-73,142,390 (619bp) & 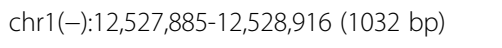 & WUGSC 2.0.2/ponAbe2 \\
\hline \multirow[t]{2}{*}{ Gibbon } & chr2(+):158,448,609-158,449,280 (672bp) & $\operatorname{chr17}(-): 95,524,509-95,526,825$ (2317bp) & GGSC Nleu3.0/nomLeu3 \\
\hline & & chr20(-):83,814,471-83,814,741 (271bp) & \\
\hline Rhesus & chr20(+):83,708,139-83,710,782 (2644bp) & N/A & BGI CR_1.0/rheMac3 \\
\hline Cow & chr18(+):10,576,131-10.576,179 (49bp) & N/A & Baylor Btau_4.6.1/bosTau7 \\
\hline Dog & $\operatorname{chr5(+):67,222,084-67,222,093~(10bp)~}$ & chr28(-):35,919,958-35,920,624 (667bp) & Broad CanFam3.1/canFam3 \\
\hline \multirow[t]{2}{*}{ Rat } & $\operatorname{chr14(+):3,644,385-3,645,161~(777bp)~}$ & chr8(-):60,446,61-60,465,11 (1851bp) & RGSC 5.0/rn5 \\
\hline & & chr12(+):82,176,55-82,180,67 (413bp) & \\
\hline \multirow[t]{3}{*}{ Mouse } & chr2(+):167,074,771-167,075,545 (775bp) & chr3(+):79,000,591-79,000,853 (263bp) & $\mathrm{GRCm} 38 / \mathrm{mm} 10$ \\
\hline & & chr3(-):144,489,926-144,491,349 (1424bp) & \\
\hline & & chr10(-):121,578,768-121,580,330 (1563bp) & \\
\hline \multirow[t]{3}{*}{ Zebra fish } & chr16(+):8,911,924-8,912,616 (693bp) & chr4(+):44,314,003-44,315,463 (1461bp) & Zv9/danRer7 \\
\hline & & chr8(+):41,186,318-41,186,865 (548bp) & \\
\hline & & chr15(-):11,992,633-11,992,908 (276bp) & \\
\hline
\end{tabular}

inform on the expression levels of FOXF1 in our patients. Hence, to determine whether FOXF1 could be functionally over-expressed in the patients, we studied the involvement of its upstream regulatory elements in the duplicated segments, as well as their parental origin, given the incomplete paternal genomic imprinting of FOXF1 in the human lungs [6,7].

Genomic duplications excluding regulatory elements of dosage-sensitive genes have been proposed to lead to inefficient transcription of the extra gene copy and lack of functional consequences. Amor et al. [29] reported an $\sim 88 \mathrm{~kb}$ duplication at $14 \mathrm{q} 12$, encompassing the dosage-sensitive FOXG1 gene in a father-son pair with isolated hemifacial microsomia. Neither the son nor the father exhibited ID or epilepsy. The authors questioned the pathogenicity of the increased dosage of FOXG1. However, this duplication did not include the distant cis-regulatory elements of FOXG1 [30-33]. Moreover, a 7.4-kb cis-regulatory deletion disrupting conserved noncoding sequences and their interaction with the promoter of another FOX gene, FOXL2, mapping more than $280 \mathrm{~kb}$ apart, has been described as pathogenic for blepharophimosis, ptosis, and epicanthus inversus (BPES; OMIM 110100) [34]. This suggests that the presence of long-range regulatory elements could be a more general phenomenon common to the forkhead family FOX genes and highlights the importance of determining the exact location of the duplication breakpoints.

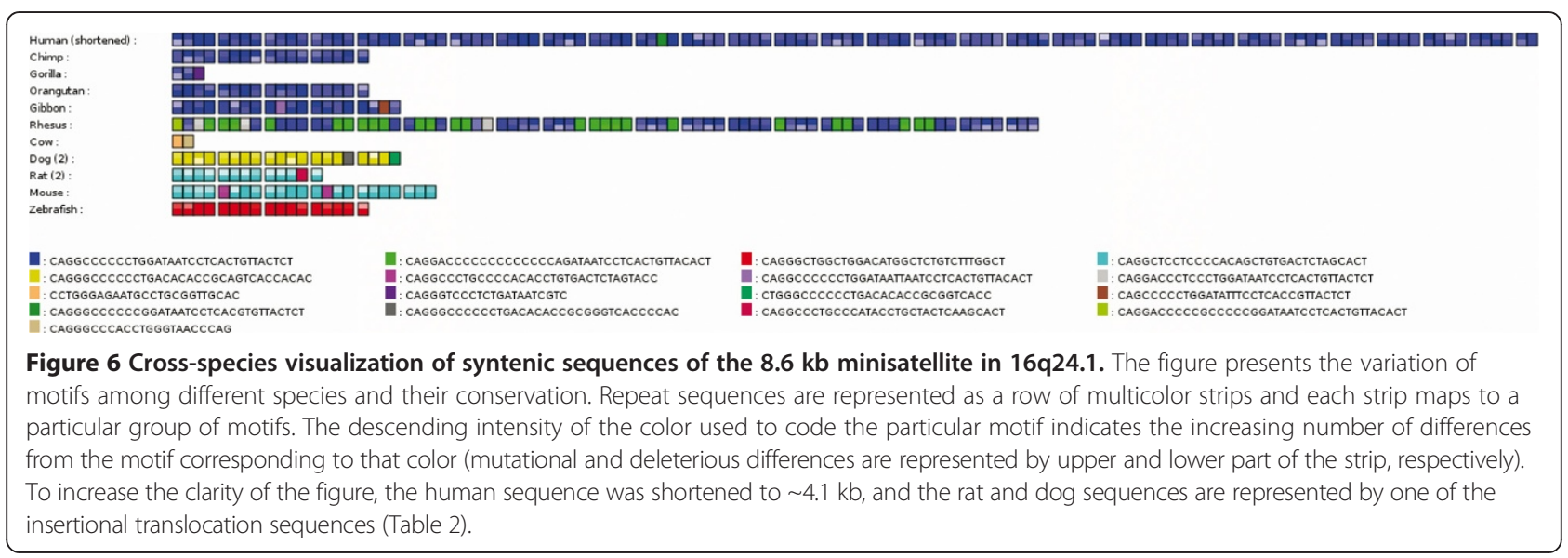


In family 1 , the distant regulatory element upstream of FOXF1 is not duplicated. The duplicated exon 1 and part of the $1^{\text {st }}$ intron of the FENDRR transcript is likely nonfunctional (Figure 2a), leaving the duplicated copy of FOXF1 devoid of its distant upstream cis-regulatory element which maps $272 \mathrm{~kb}$ upstream (chr16:86,212,040 86,271,915) [6,7]. Additionally, given the fact that the duplication is inherited from the father, the increase of FOXF1 dosage in patient 1 is probably minimal, if any. Similarly, the FOXF1 duplication in patient 2 does not encompass the distant upstream cis-enhancer, and is paternally inherited. Hence, the increase in the expression level of FOXF1 in patient 2 may also be minor. Conversely, the lung-specific enhancer region is duplicated in patients 3 and 4 . However given the similarity in symptoms between patient 3 and her father, the duplication in patient 3 is likely paternally inherited and, the increase of FOXF1 expression in patient $3 \mathrm{~s}$ lungs is likely minimal. In contrast, as the duplication in patient $3 \mathrm{~s}$ daughter and patient 4 arose on the maternal chromosome, the duplicated FOXF1 copy in these patients is likely functional and associated with an increase of FOXF1 expression in the lungs.

Along with mild dysmorphic features, patient 1 has one caf-au-lait macule on his left flank and speech delay, typical features of Neurofibromatosis type 1 (NF1; OMIM 162200). Hence, speech delay and other abnormalities in the proband likely result from the NF1 deletion [35] rather than from the FOXF1 duplication. This notion is further supported by the fact that the father with isolated FOXF1 duplication was reportedly healthy.

In addition to the FOXF1 duplication on 16q24.1, patient 2 has two duplications on 16q23.3 and 16q24.2. The 16q23.3 duplication is also inherited from the father with bipolar disorder, suggesting that genes other than FOXF1 may be responsible for the patients autistic and emotional disorders.

Recently, a patient harboring a complex de novo duplication-triplication rearrangement in 16q24.1-q24.3 was reported [36]. The patient presented with severe psychomotor disability, numerous dysmorphic features, and congenital malformations, including gut malrotation and gall bladder agenesis. The phenotype in the patient was attributed to the increased dosage of FOXF1, FOXC2, ANKRD11, SPG7, and FANCA in the duplicated/triplicated regions. Segregation of gastrointestinal abnormalities with FOXF1 duplication in family 3 indicates that FOXF1 is incompletely paternally imprinted only in the human lungs [6] and that the gastrointestinal symptoms in this family may be due to overexpression of FOXF1 in the intestine.

Interestingly, maternal uniparental disomy of chromosome 16 usually associated with mosaic trisomy 16 , and thus resulting in even higher dosage of FOXF1 is associated with pulmonary hypoplasia, congenital heart defects, tracheosophageal fistula, gut malrotation, and renal agenesis in addition to intrauterine growth restriction [37], suggesting FOXF1 expression higher than that in constitutional duplications may influence development of organs typically affected in patients with ACDMPV.

The presence of ID and speech delay in patient 4 may result from the duplication of other genes in the duplicated segment on 16q24.1. This notion is further supported by another Decipher patient 265650 with a de novo $\sim 0.26 \mathrm{Mb}$ duplication at chr16:85,678,461-85,942,847 (leaving FOXF1 intact) and presenting with ID and delayed speech and language development. This duplication involves the C16orf74, COX4I1, EMC8, GINS2, GSE1, and IRF8 genes that are also duplicated in patient 4 . The absence of any lung defects in all four patients suggests that constitutional duplication of FOXF1 is likely not pathogenic in the human lungs.

Interestingly, the duplication in patient 4 mapping distal and adjacent to a large minisatellite contains in its junction fragment, truncated segments of this minisatellite. We found this minisatellite is highly polymorphic in the general population, with many deletions and duplications reported in DGV as well as in several control DNA samples analyzed on our customized high-resolution 16q24.1 $\mathrm{CGH}$ microarrays (Figure 5), indicating that it contracts and expands. The orthologous VNTRs of this minisatellite in several species are much shorter and range from $597 \mathrm{bp}$ in Chimp to 2,644 bp in Rhesus (Figure 6, Table 2), demonstrating its high instability during the evolution of the human genome. Amplification of this region in chimp and Rhesus genomes showed that, similar to human genome, this VNTR is polymorphic (Additional file 1: Figure S4).

Genome-wide bioinformatic analyses showed that when classified based on repeat length, the density of minisatellites greater than $1 \mathrm{~kb}$ in length is highest in the pericentromeric and subtelomeric regions. Conversely, VNTRs shorter than $1 \mathrm{~kb}$ in length are found to cluster primarily away from the pericentromeric regions (Additional file 1: Figure S8). PCR amplification of the minisatellite located at 16q24.1 in the mother of patient 4 revealed that it is truncated $(\sim 2 \mathrm{~kb})$ when compared to the reference human genome $(\sim 8.6 \mathrm{~kb})$. We suggest that the smaller size of this minisatellite in the mother of patient 4 might have undergone an incomplete heterochromatinization, predisposing it to a higher rate of DNA replication errors [38] and subsequent formation of the complex rearrangement via break-induced replication (BIR) or microhomology-mediated break-induced replication (MMBIR) [39,40]. We propose the microduplication arose pre-meiotically, as a mitotic DNA replication error in the patient $4 \mathrm{~s}$ mother (Figure 4e). A DNA replication slippage within the minisatellite led to 
the 8 bp GAGCAGCC insertion and subsequent strand invasion at chr16(-):86,978,360. A 2 bp GC microhomology mediated another template switch in the reverse direction from chr16(-):86,979,735 to chr16(+):87,102,896 and a 2 bp CA microhomology might have mediated another template switch in the forward direction from chr16(+):87,102,675 to chr16(+):87,168,469. This resulted in a triplication of the segments chr16(+):87,102,67587,102,896 (221 bp) (yellow block) and chr16(-):86,978, 360-86,979,735 (1375 bp) (green block), in addition to the duplication observed (Figure 4e). A high frequency of small deletions and insertions, likely originating from polymerase slippage events at breakpoint junctions of complex copy-number variants, have recently been reported in patients with $M E C P 2$ duplications [41]. In addition, analyses of structural variation from the first sequenced personal genome [42,43] showed that minisatellites were responsible for $25.8 \%$ of medium-sized $(<10 \mathrm{~kb})$ structural variants [44]. Interestingly, intersection of VNTRs larger than $1 \mathrm{~kb}$ with uncertain CNV breakpoint regions (between minimum and maximum coordinates) smaller than $20 \mathrm{~kb}$ in size identified in 16,886 patients from the CMA database of 39,729 patients analyzed at MGL, revealed 156 unique $\mathrm{CNVs}$, suggesting some of them might have also been mediated by long minisatellites (Additional files 1 and 2: Table S2).

\section{Conclusions}

In aggregate, we describe 16q24.1 duplications involving FOXF1 in four unrelated families with speech delay, ID, and gastrointestinal abnormalities. The lack of any pulmonary symptoms in these patients suggests relatively benign pediatric pulmonary consequences of FOXF1 overexpression due to constitutional duplications. Discerning the effects of FOXF1 overexpression or ectopic expression is of primary importance for any future work towards FOXF1-based gene therapies for ACDMPV and other disorders caused by FOXF1 abnormal dosage. Given the findings in family 3 and the fact that FOXF1 alterations were associated with intestinal abnormalities $[2,4,36,45]$, we propose that patients with gut malrotation, pyloric or duodenal stenosis, or gall bladder agenesis should be tested for FOXF1 mutations and CNVs.

Moreover, our analyses revealed an evolutionarily unstable and highly polymorphic minisatellite in 16q24.1. We propose that instability of minisatellites greater than $1 \mathrm{~kb}$ can lead to genomic structural variation due to DNA replication errors.

\section{Consent}

Written informed consent approved by the Institutional Review Board (IRB) at BCM was obtained from patients 1, 2, 3 as well as patient $2 \mathrm{~s}$ father and patient
$3 \mathrm{~s}$ daughter for publication of this report and any accompanying images. In case of minors, consent was obtained from their parent. Written informed consent for publication of this report and any accompanying images approved by the IRB at Saint Vincent de Paul Catholic Hospitals Association of Lille, Free Faculty of Medicine, Lille, France was obtained from patient 4 and both his parents.

\section{Additional files}

Additional file 1: Supplementary Information. Molecular and clinical analyses of 16q24.1 duplications involving FOXF1 identify an evolutionarily unstable large minisatellite.

Additional file 2: Table S2. Intersection of VNTRs ( $>1 \mathrm{~kb}$ ) with uncertain CNV breakpoint regions ( $<20 \mathrm{~kb}$ ) from the CMA database at MGL.

\section{Competing interests}

The authors declare that they have no competing interests.

\section{Authors contributions}

Conceived and designed the experiments: AVD, PSz, TG, and PS. Performed the experiments: AVD, PSz, WC, and WJ. Analyzed the data: AVD, PSz, TG, FJP, $P F, K G, A G$, and PS. Contributed samples/analysis tools: JKG-A, SG, FB, BD-B, $B D, J A, K B, E H-F$, and SWC. Wrote the paper: AVD and PS. All authors read and approved the final manuscript.

\section{Acknowledgements}

We thank Drs. C.R. Beck, C.M. Carvalho, G. Ira, P. Liu, J.R. Lupski, and F. Zhang, for helpful discussion. This study makes use of data generated by the Decipher Consortium. A full list of centers who contributed to the generation of the data is available from http://decipher.sanger.ac.uk and via email from decipher@sanger.ac.uk. Funding for the project was provided by the Wellcome Trust. This work was supported by NIH grant 1RO1HL101975 to P.S. F.J.P. is supported by a Burroughs Wellcome Fund Career Award for Medical Scientists.

\section{Author details}

${ }^{1}$ Interdepartmental Program in Translational Biology \& Molecular Medicine, Baylor College of Medicine, Houston, TX, USA. ${ }^{2}$ Department of Molecular and Human Genetics, Baylor College of Medicine, One Baylor Plaza, Houston, TX 77030, USA. ${ }^{3}$ Institute of Informatics, University of Warsaw, Warsaw, Poland. ${ }^{4}$ Mossakowski Medical Research Center, Polish Academy of Sciences, Warsaw, Poland. ${ }^{5}$ Specially for Children, Dell s Children s Medical Center, Austin, TX, USA. ${ }^{6}$ Departments of Pediatrics and Neurology, University of Texas Southwestern Medical Center, Dallas, TX, USA. ${ }^{7}$ Neuropediatrics Service, Saint Vincent de Paul Catholic Hospitals Association of Lille, Free Faculty of Medicine, Lille, France. ${ }^{8}$ Cytogenetics Service, Saint Vincent de Paul Catholic Hospitals Association of Lille, Free Faculty of Medicine, Lille, France.

${ }^{9}$ Laboratory of Medical Genetics, University Hospital, Lille, France. ${ }^{10}$ Medical Genetics Center, Munich, Germany.

Received: 12 May 2014 Accepted: 18 November 2014 Published online: 04 December 2014

\section{References}

1. Langston C: Misalignment of pulmonary veins and alveolar capillary dysplasia. Pediatr Pathol 1991, 11:163 170.

2. Stankiewicz P, Sen P, Bhatt SS, Storer M, Xia Z, Bejjani BA, Ou Z, Wiszniewska J, Driscoll DJ, Maisenbacher MK, Bolivar J, Bauer M, Zackai EH, McDonaldMcGinn D, Nowaczyk MM, Murray M, Hustead V, Mascotti K, Schultz R, Hallam L, McRae D, Nicholson AG, Newbury R, Durham-O'Donnell J, Knight G, Kini U, Shaikh TH, Martin V, Tyreman M, Simonic I, et al: Genomic and genic deletions of the FOX gene cluster on 16q24.1 and inactivating mutations of FOXF1 cause alveolar capillary dysplasia and other malformations. Am J Hum Genet 2009, 84:780 791 
3. Bishop NB, Stankiewicz P, Steinhorn RH: Alveolar capillary dysplasia. Am J Respir Crit Care Med 2011, 184:172 179.

4. Sen P, Thakur N, Stockton DW, Langston C, Bejjani BA: Expanding the phenotype of alveolar capillary dysplasia (ACD). J Pediatr 2004, 145:646 651.

5. Sen $P$, Yang Y, Navarro C, Silva I, Szafranski $P$, Kolodziejska KE, Dharmadhikari AV, Mostafa H, Kozakewich H, Kearney D, Cahill JB, Whitt M, Bilic M, Margraf L, Charles A, Goldblatt J, Gibson K, Lantz PE, Garvin AJ, Petty J, Kiblawi Z, Zuppan C, McConkie-Rosell A, McDonald MT, Peterson-Carmichael SL, Gaede JT, Shivanna B, Schady D, Friedlich PS, Hays SR, et al: Novel FOXF1 mutations in sporadic and familial cases of alveolar capillary dysplasia with misaligned pulmonary veins imply a role for its DNA binding domain. Hum Mutat 2013, 34:801 811

6. Szafranski P, Dharmadhikari AV, Brosens E, Gurha P, Kolodziejska KE, Zhishuo O, Dittwald P, Majewski T, Mohan KN, Chen B, Person RE, Tibboel D, De Klein A, Pinner J, Chopra M, Malcolm G, Peters G, Arbuckle S, Guiang SF III, Hustead VA, Jessurun J, Hirsch R, Witte DP, Maystadt I, Sebire N, Fisher R, Langston C, Sen P, Stankiewicz P: Small noncoding differentially methylated copy-number variants, including IncRNA genes, cause a lethal lung developmental disorder. Genome Res 2013, 23:23 33

7. Szafranski P, Dharmadhikari AV, Wambach JA, Towe CT, White FV, Grady RM, Eghtesady P, Cole FS, Deutsch G, Sen P, Stankiewicz P: Two deletions overlapping a distant FOXF1 enhancer unravel the role of IncRNA LINC01081 in etiology of alveolar capillary dysplasia with misalignment of pulmonary veins. Am J Med Genet A 2014, 164A:2013 2019.

8. Sen P, Gerychova R, Janku P, Jezova M, Valaskova I, Navarro C, Silva I, Langston C, Welty S, Belmont J, Stankiewicz P: A familial case of alveolar capillary dysplasia with misalignment of pulmonary veins supports paternal imprinting of FOXF1 in human. Eur J Hum Genet 2013, 21:474 477.

9. Khalil AM, Guttman M, Huarte M, Garber M, Raj A, Rivea Morales D, Thomas K, Presser A, Bernstein BE, van Oudenaarden A, Regev A, Lander ES, Rinn JL: Many human large intergenic noncoding RNAs associate with chromatin-modifying complexes and affect gene expression. Proc Natl Acad Sci U S A 2009, 106:11667 11672.

10. Mahlapuu M, Ormestad M, Enerbck S, Carlsson P: The forkhead transcription factor Foxf1 is required for differentiation of extra-embryonic and lateral plate mesoderm. Development 2001, 128:155 166

11. Mahlapuu M, Enerback S, Carlsson P: Haploinsufficiency of the forkhead gene Foxf1, a target for sonic hedgehog signaling, causes lung and foregut malformations. Development 2001, 128:2397 2406

12. Kalinichenko W, Lim L, Stolz DB, Shin B, Rausa FM, Clark J, Whitsett JA, Watkins SC, Costa RH: Defects in pulmonary vasculature and perinatal lung hemorrhage in mice heterozygous null for the Forkhead Box f1 transcription factor. Dev Biol 2001, 235:489 506

13. Ren X, Ustiyan V, Pradhan A, Cai Y, Havrilak JA, Bolte CS, Shannon JM, Kalin TV, Kalinichenko W: FOXF1 transcription factor is required for formation of embryonic vasculature by regulating VEGF signaling in endothelial cells. Circ Res 2014, [Epub ahead of print].

14. Grote P, Wittler L, Hendrix D, Koch F, Whrisch S, Beisaw A, Macura K, Blss G, Kellis M, Werber M, Hermann BG: The tissue-specific IncRNA Fendrr is an essential regulator of heart and body wall development in the mouse. Dev Cell 2013, 24:206 214.

15. Sauvageau M, Goff LA, Lodato S, Bonev B, Groff AF, Gerhardinger C, Sanchez-Gomez DB, Hacisuleyman E, Li E, Spence M, Liapis SC, Mallard W, Morse M, Swerdel MR, D'Ecclessis MF, Moore JC, Lai V, Gong G, Yancopoulos GD, Frendewey D, Kellis M, Hart RP, Valenzuela DM, Arlotta P, Rinn JL: Multiple knockout mouse models reveal lincRNAs are required for life and brain development. Elife 2013, 2:e01749.

16. Lo PK, Lee JS, Liang X, Han L, Mori T, Fackler MJ, Sadik H, Argani P, Pandita TK, Sukumar S: Epigenetic inactivation of the potential tumor suppressor gene FOXF1 in breast cancer. Cancer Res 2010, 70:6047 6058.

17. Su Z, Gay LJ, Strange A, Palles C, Band G, Whiteman DC, Lescai F, Langford C, Nanji M, Edkins S, van der Winkel A, Levine D, Sasieni P, Bellenguez C, Howarth K, Freeman C, Trudgill N, Tucker AT, Pirinen M, Peppelenbosch MP, van der Laan LJ, Kuipers EJ, Drenth JP, Peters WH, Reynolds JV, Kelleher DP, McManus R, Grabsch H, Prenen H, Bisschops R, et al: Common variants at the MHC locus and at chromosome $16 \mathrm{q} 24.1$ predispose to Barrett's esophagus. Nat Genet 2012, 44:1131 1136.

18. Levine DM, Ek WE, Zhang R, Liu X, Onstad L, Sather C, Lao-Sirieix P, Gammon MD, Corley DA, Shaheen NJ, Bird NC, Hardie LJ, Murray LJ, Reid BJ, Chow WH, Risch HA, Nyrn O, Ye W, Liu G, Romero Y, Bernstein L, Wu AH,
Casson AG, Chanock SJ, Harrington P, Caldas I, Debiram-Beecham I, Caldas C, Hayward NK, Pharoah PD, et al: A genome-wide association study identifies new susceptibility loci for esophageal adenocarcinoma and Barrett's esophagus. Nat Genet 2013, 45:1487 1493.

19. Nilsson J, Helou K, Kovcs A, Bendahl PO, Bjursell G, Fern M, Carlsson P, Kannius-Janson M: Nuclear Janus-activated kinase 2/nuclear factor 1-C2 suppresses tumorigenesis and epithelial-to-mesenchymal transition by repressing Forkhead box F1. Cancer Res 2010, 70:2020 2029.

20. Armeanu-Ebinger S, Bonin M, Hbig K, Poremba C, Koscielniak E, Godzinski J, Warmann SW, Fuchs J, Seitz G: Differential expression of invasion promoting genes in childhood rhabdomyosarcoma. Int J Oncol 2011, 38:993 1000.

21. Lo PK, Lee JS, Chen H, Reisman D, Berger FG, Sukumar S: Cytoplasmic mislocalization of overexpressed FOXF1 is associated with the malignancy and metastasis of colorectal adenocarcinomas. Exp Mol Pathol 2013, 94:262 269.

22. Ellegren $\mathrm{H}$ : Microsatellites: simple sequences with complex evolution. Nat Rev Genet 2004, 5:435 445.

23. Gemayel R, Vinces MD, Legendre M, Verstrepen $\mathrm{KJ}$ : Variable tandem repeats accelerate evolution of coding and regulatory sequences. Annu Rev Genet 2010, 44:445 477

24. Szafranski P, Schaaf CP, Person RE, Gibson IB, Xia Z, Mahadevan S, Wiszniewska J, Bacino CA, Lalani S, Potocki L, Kang SH, Patel A, Cheung SW, Probst FJ, Graham BH, Shinawi M, Beaudet AL, Stankiewicz P: Structures and molecular mechanisms for common $15 q 13.3$ microduplications involving CHRNA7: benign or pathological? Hum Mutat 2010, 31:840 850

25. Szafranski P, Yang Y, Nelson MU, Bizzarro MJ, Morotti RA, Langston C, Stankiewicz P: Novel FOXF1 deep intronic deletion causes lethal lung developmental disorder alveolar capillary dysplasia with misalignment of pulmonary veins. Hum Mutat 2013, 34:1467 1471

26. Benson G: Tandem repeats finder: a program to analyze DNA sequences. Nucleic Acids Res 1999, 27:573 580.

27. Kehrer-Sawatzki H, Kluwe L, Sandig C, Kohn M, Wimmer K, Krammer U, Peyrl A, Jenne DE, Hansmann I, Mautner VF: High frequency of mosaicism among patients with neurofibromatosis type 1 (NF1) with microdeletions caused by somatic recombination of the JJAZ1 gene. Am J Hum Genet 2004, 75:410 423

28. Steinmann K, Cooper DN, Kluwe L, Chuzhanova NA, Senger C, Serra E, Lazaro C, Gilaberte M, Wimmer K, Mautner VF, Kehrer-Sawatzki H: Type 2 NF1 deletions are highly unusual by virtue of the absence of nonallelic homologous recombination hotspots and an apparent preference for female mitotic recombination. Am J Hum Genet 2007, 81:1201 1220.

29. Amor DJ, Burgess T, Tan TY, Pertile MD: Questionable pathogenicity of FOXG1 duplication. Eur J Hum Genet 2012, 20:595 596.

30. Kortm F, Das S, Flindt M, Morris-Rosendahl DJ, Stefanova I, Goldstein A, Horn D, Klopocki E, Kluger G, Martin P, Rauch A, Roumer A, Saitta S, Walsh LE, Wieczorek D, Uyanik G, Kutsche K, Dobyns WB: The core FOXG1 syndrome phenotype consists of postnatal microcephaly, severe mental retardation, absent language, dyskinesia, and corpus callosum hypogenesis. J Med Genet 2011, 48:396 406.

31. Brunetti-Pierri N, Paciorkowski AR, Ciccone R, Della Mina E, Bonaglia MC, Borgatti R, Schaaf CP, Sutton VR, Xia Z, Jelluma N, Ruivenkamp C, Bertrand M, de Ravel TJ, Jayakar P, Belli S, Rocchetti K, Pantaleoni C, D'Arrigo S, Hughes J, Cheung SW, Zuffardi O, Stankiewicz P: Duplications of FOXG1 in $14 q 12$ are associated with developmental epilepsy, mental retardation, and severe speech impairment. Eur J Hum Genet 2011, 19:102 107.

32. Falace A, Vanni N, Mallamaci A, Striano P, Zara F: Do regulatory regions matter in FOXG1 duplications? Eur J Hum Genet 2013, 21:365 366.

33. Ellaway CJ, Ho G, Bettella E, Knapman A, Collins F, Hackett A, McKenzie F, Darmanian A, Peters GB, Fagan K, Christodoulou J: 14q12 microdeletions excluding FOXG1 give rise to a congenital variant Rett syndrome-like phenotype. Eur J Hum Genet 2013, 21:522 527.

34. D'haene B, Attanasio C, Beysen D, Dostie J, Lemire E, Bouchard P, Field M, Jones K, Lorenz B, Menten B, Buysse K, Pattyn F, Friedli M, Ucla C, Rossier C, Wyss C, Speleman F, De Paepe A, Dekker J, Antonarakis SE, De Baere E: Disease-causing $7.4 \mathrm{~kb}$ cis-regulatory deletion disrupting conserved noncoding sequences and their interaction with the FOXL2 promotor: implications for mutation screening. PLoS Genet 2009, 5:e1000522.

35. Gutmann DH, Aylsworth A, Carley JC, Korf B, Marks J, Pyeritz RE, Rubenstein A, Viskochil D: The diagnostic evaluation and multidisciplinary management of neurofibromatosis 1 and neurofibromatosis 2. JAMA 1997, 278:51 57. 
36. Kucharczyk M, Kochański A, Jezela-Stanek A, Kugaudo M, Sielska-Rotblum D, Gutkowska A, Krajewska-Walasek M: The first case of a patient with de novo partial distal $16 q$ tetrasomy and a data's review. Am J Med Genet A 2014, 164A:2541 2550. doi:10.1002/ajmg.a.36686.

37. Yong PJ, Marion SA, Barrett IJ, Kalousek DK, Robinson WP: Evidence for imprinting on chromosome 16: the effect of uniparental disomy on the outcome of mosaic trisomy 16 pregnancies. Am J Med Genet 2002, 112:123 132. 389 .

38. Zaratiegui M, Vaughn MW, Irvine DV, Goto D, Watt S, Bhler J, Arcangioli B, Martienssen RA: CENP-B preserves genome integrity at replication forks paused by retrotransposon LTR. Nature 2011, 469:112 115 .

39. Hastings PJ, Ira G, Lupski JR: A microhomology-mediated break-induced replication model for the origin of human copy number variation. PLOS Genet 2009, 5:e1000327.

40. Malkova A, Ira G: Break-induced replication: functions and molecular mechanism. Curr Opin Genet Dev 2013, 23:271 279.

41. Carvalho CM, Pehlivan D, Ramocki MB, Fang P, Alleva B, Franco LM, Belmont JW, Hastings PJ, Lupski JR: Replicative mechanisms for CNV formation are error prone. Nat Genet 2013, 45:1319 1326.

42. Levy S, Sutton G, Ng PC, Feuk L, Halpern AL, Walenz BP, Axelrod N, Huang J, Kirkness EF, Denisov G, Lin Y, MacDonald JR, Pang AW, Shago M, Stockwell TB, Tsiamouri A, Bafna V, Bansal V, Kravitz SA, Busam DA, Beeson KY, McIntosh TC, Remington KA, Abril JF, Gill J, Borman J, Rogers YH, Frazier ME, Scherer SW, Strausberg RL, et al: The diploid genome sequence of an individual human. PLOS Biol 2007, 5:e254.

43. Pang AW, MacDonald JR, Pinto D: Towards a comprehensive structural variation map of an individual human genome. Genome Biol 2010, 11:R52.

44. Pang AW, Migita O, Macdonald JR, Feuk L, Scherer SW: Mechanisms of formation of structural variation in a fully sequenced human genome. Hum Mutat 2013, 34:345 354.

45. Kalinichenko W, Zhou Y, Bhattacharyya D, Kim W, Shin B, Bambal K, Costa $\mathrm{RH}$ : Haploinsufficiency of the mouse Forkhead Box $\mathrm{f1}$ gene causes defects in gall bladder development. J Biol Chem 2002, 277:12369 12374.

\section{Submit your next manuscript to BioMed Central and take full advantage of:}

$\bowtie$ Convenient online submission

$\otimes$ Thorough peer review

$\nabla$ No space constraints or color $\nabla$ gure charges

$\otimes$ Immediate publication on acceptance

\Inclusion in PubMed, CAS, Scopus and Google Scholar

$\otimes$ Research which is freely available for redistribution 